Трегубова Ю. А. Способы модификации и семантика иностранных антропонимов в русскоязычном интернет-дискурсе (на примере номинации членов Британской королевской семьи) / Ю. А. Трегубова, Е. В. Лаврищева // Научный диалог. - 2021. — № 9. - С. 113127. - DOI: 10.24224/2227-1295-2021-9-113-127.

Tregubova, Y. A., Lavrishcheva, E. V. (2021). Methods of Modification and Semantics of Foreign Anthroponyms in Russian Internet Discourse (Example of Nomination of Members of British Royal Family). Nauchnyi dialog, 9: 113-127. DOI: 10.24224/2227-1295-2021-9-113127. (In Russ.).

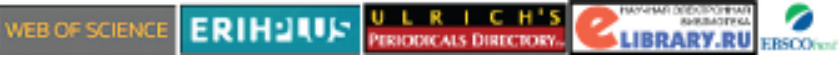

Журнал включен в Перечень ВАК

Способы модификации

и семантика иностранных

антропонимов

В русскоязычном

интернет-дискурсе

(на примере номинации

членов Британской

королевской семьи)

Трегубова Юлия Алексеевна

orcid.org/0000-0002-0864-4543

кандидат филологических наук, доцент

кафедра романо-германских языков

и перевода

tregubova@elsu.ru

Лаврищева Екатерина Владимировна orcid.org/0000-0002-4218-718X

кандидат филологических наук, доцент кафедра романо-германских языков

и перевода

eklav@mail.ru

Елецкий государственный университет им. И. А. Бунина

(Елец, Россия)

\section{Methods of Modification and Semantics of Foreign Anthroponyms \\ in Russian Internet Discourse (Example of Nomination of Members of British Royal Family)}

Yulia A. Tregubova

orcid.org/0000-0002-0864-4543

$\mathrm{PhD}$ in Philology, Associate Professor

Departament of Romance-Germanic

Languages and Translation tregubova@elsu.ru

Ekaterina V. Lavrishcheva orcid.org/0000-0002-4218-718X

$\mathrm{PhD}$ in Philology, Associate Professor Departament of Romance-Germanic

Languages and Translation eklav@mail.ru

Bunin Yelets State University (Yelets, Russia)

(C) Трегубова Ю. А., Лаврищева Е. В., 2021 


\section{ОРИГИНАЛЬНЫЕ СТАТЬИ}

\section{Аннотация:}

Представлены результаты исследования особенностей функционирования модифицированных иностранных антропонимов в русскоязычном интернет-дискурсе. Рассматриваются основные способы словообразования, структура и семантика иностранных окказиональных антропонимов в русскоязычном интернет-дискурсе. Актуальность и новизна исследования обусловлены выбором языкового материала, в качестве которого выбраны иноязычные антропонимы в русском языке, в частности, модифицированные имена членов Британской королевской семьи, выражающие эмоционально-оценочные суждения русскоязычных пользователей сети Интернет. Приводятся результаты структурного и сопоставительного анализа модифицированных иностранных антропонимов, используемых русскоязычными интернет-пользователями. Предпринята попытка показать, как словообразовательные средства русского языка могут отражать субъективную коннотацию окказиональных дериватов. Выявлены основные словообразовательные модели в области окказиональной антропонимики русского языка. Сделан вывод о том, что наиболее продуктивным способом модификации иностранных антропонимов в русскоязычном интернет-дискурсе является суффиксация. Анализируется семантика выявленных словообразовательных моделей, изучается их эмоционально-экспрессивная функция в языке. Приводятся результаты статистического анализа применения основных способов создания модифицированных иностранных антропонимов в русскоязычном интернет-дискурсе.

\section{Ключевые слова:}

антропонимы; модификация иностранных антропонимов; Британская королевская семья; суффиксация; сокращение; ономастическая игра.

\section{ORIGINAL ARTICLES}

\section{Abstract:}

The results of a study of the functioning peculiarities of modified foreign anthroponyms in the Russian-language Internet discourse is presented in the article. The main methods of word formation, the structure and semantics of foreign occasional anthroponyms in the Russianlanguage Internet discourse are considered. The relevance and novelty of the study is due to the choice of linguistic material, which were foreign-language anthroponyms in Russian, in particular, modified names of members of the British royal family. It is shown that these occasional nominations embody the emotional and evaluative attitude of Russian-speaking Internet users to members of the royal family. The results of a structural and comparative analysis of modified foreign anthroponyms used by Russian-speaking Internet users are presented. An attempt is made to show how the derivational means of the Russian language can reflect the subjective connotation of occasional derivatives. The main word-formation models in the field of occasional anthroponymy of the Russian language are revealed. It is concluded that the most productive way of modifying foreign anthroponyms in the Russian-language Internet discourse is suffixation. The semantics of the identified word-formation models is analyzed, their emotional-expressive function in the language is studied. The results of a statistical analysis of the use of the main methods of creating modified foreign anthroponyms in the Russian-language Internet discourse are presented.

\section{Key words:}

anthroponyms; modification of foreign anthroponyms; British royal family; suffixation; reduction; onomastic game. 
УДК 811.161.1’373.23

\section{Способы модификации и семантика иностранных} антропонимов в русскоязычном интернет-дискурсе (на примере номинации членов Британской королевской семьи)

() Трегубова Ю. А., Лаврищева Е. В., 2021

\section{1. Введение}

Сегодня Интернет, являясь одним из основных медиасредств, дает людям почти неограниченные возможности для общения и самовыражения. Как отмечают исследователи современных массмедиа, «компьютерноопосредованная форма коммуникации - это способ быстрого получения информации, возможность общения людей, находящихся в разных частях света, независимо от их расы, общественного положения, рода занятий и возраста» [Зимина и др., 2014, с. 67].

Любой человек может создавать свои интернет-каналы, публиковать статьи и комментировать записи других пользователей. Интернет-среда в современных условиях - это не только средство получения информации, но и неотъемлемая часть культуры любого общества, где пользователи сети могут посредством комментариев, выражать свое мнение о различных событиях и известных личностях. Антропонимы во всем их многообразии являются неотъемлемой частью современного русскоязычного интернет-дискурса [Гудым, 2014; Замальдинов, 2019].

Как показывает анализ статей русскоязычных интернет-пользователей, большой интерес и обсуждение вызывают не только отечественные медиаличности (политики, артисты, спортсмены и др.), но и представители иноязычных культур. Особое внимание в русскоязычных блогах и статьях уделяется жизни Британской королевской семьи (далее также - БКС).

Британская монархия - одна из старейших в Европе (существует с 827 года). Жизнь членов Британской королевской семьи всегда привлекала внимание людей во всем мире. Кроме того, события нескольких последних лет активно обсуждаются людьми во многих странах, в том числе и в России. В русскоязычной сети Интернет можно найти множество частных публикаций, посвященных событиям, происходящим в Британском королевском доме, а также статьи почти о каждом члене семьи.

Наибольший интерес у аудитории вызывает новое поколение: принцы Уильям и Гарри и их семьи. Проведя анализ частных русскоязычных публикаций, мы выяснили, что читателей интересовали события, проис- 
ходившие с четой Кембриджей (Уильям и Кейт), Сассекских (Гарри и Меган Маркл). В сети обсуждались свадьбы обоих принцев, поведение обеих герцогинь и их взаимоотношения друг с другом и членами семьи, скандальный «Мегзит» и его последствия для Британской королевской семьи, смерть и похороны принца Филиппа.

Отношение русскоговорящей аудитории к обсуждаемым персонам довольно неоднозначно, пользователи не стесняются высказывать в комментариях свое восхищение или неодобрение. Следует отметить тот факт, что положительное или негативное мнение аудитории выражается в том числе и в создании модифицированных антропонимов членов Британской королевской семьи. Так, для выражения нейтрального или положительного отношения к обсуждаемым персонам пользователи употребляли официальные имена представителей правящей династии, например: Королева Великобритании: Елизавета II, Елизавета, Королева; Филип, принц Эдинбургский Филип; Чарльз, принц Уэльский — Чарльз; Камилла, герцогиня Корнуольская — Камилла; Уильям, герцог Кембриджский — Уильям, Уил; принц Гарри, герцог Сассекский - Гарри; Кэтрин, герцогиня Кембриджская - Кэтрин, Кейт; Меган, герцогиня Сассекская - Меган, Меган Маркл. Наряду с этим пользователи сети Интернет создавали различные окказиональные модифицированные варианты обсуждаемых имен, интересные с той точки зрения, что они выражают отношение к называемым лицам.

В данной статье предпринята попытка изучить словообразовательные модели модифицированных окказиональных антропонимов, выявленных в контенте Рунета (блогах и публикациях на платформе ДЗЕН), которые называют членов Британской королевской семьи, определить их семантику и специфику употребления русскоязычными пользователями. Источником языкового материала послужили тексты статей о жизни Британской королевской семьи и комментарии русскоязычных пользователей к ним. Было проанализировано 35 интернет-публикаций с общим числом комментариев более 8 тыс.

Теоретической основой нашего исследования послужили труды ученых-лингвистов, посвященные вопросам антропонимики и словообразования в русском и иностранных языках: В. Ц. Бонджоловой, Т. А. Гридиной, И. И. Зиминой, Н. В. Саварцевой, А. Г. Крыловой, К. М. Медведевой, И. В. Родионовой, М. Э. Рут и др.

\section{2. Модифицированные антропонимы членов Британской королевской семьи как материал исследования}

В результате исследования русскоязычных публикаций и комментариев в отношении представителей королевской семьи нами было выявлено 
83 модифицированных иностранных антропонима, называющих королеву Елизавету II, принца Филиппа, принца Гарри, Меган Маркл и их пары. Большая часть собственных имен употреблялась для номинации супруги принца Гарри, Меган Маркл, герцогини Сассекской - 32 антропонима (39\%); принца Гарри, герцога Сассекского - 12 лексических единиц (14\%); четы герцогов Сассекских - 11 единиц (13\%); королевы Елизаветы - 9 единиц (11\%); принца Чарльза - 4 единицы (5\%); герцогини Кетрин Кэмбриджской - 4 единицы (5 \%); принца Уильяма - 3 единицы (4\%); Арчи Сассекского - 3 единицы (4\%); принца Филиппа - 2 единицы (2 \%); принца Луи Кебриджского - 1 единица (1 \%); четы герцогов Кембриджских - 1 (1\%); других членов Британской королевской семьи - 1 единица (1\%).

Статистические данные показывают, что самое большое количество модифицированных имен было создано русскоязычными пользователями сети Интернет для наименования принца Гарри и его супруги, что объясняется повышенным интересом к событиям, происходящим в их жизни.

Следует отметить, что «модификация исходных официальных имен может быть выражена в разных формах и реализована на различных уровнях языка» [Дьяченко, 2007, с. 62]. Структурный анализ имен-окказионализмов позволил выявить некоторые особенности образования и семантики подобных модифицированных антропонимов, употреблявшихся в комментариях пользователей Рунета.

\section{3. Модели номинации представителей Британской королевской семьи в Рунете и их оценочная специфика}

В русскоязычных комментариях отмечается номинация старейших членов королевской семьи — королевы Елизаветы и принца Филиппа по схеме «личное имя + патроним» соответственно русским традициям называния по имени-отчеству: Елизавета Георгиевна (отец Елизаветы II Георг VI) и Филипn Андреевич (отец принца Филиппа - Андрей Греческий): Филипп Андреич жжет; Не судите строго, любящяая королева и бабушка Елизавета Георгиевна (орфография и пунктуация оригинальных текстов сохранены) [AА]. В данных примерах можно отметить немного ироничное, но все же уважительное отношение к королеве Великобритании и ее супругу.

Подобная модель образования креативного антропонима встречается и в комментариях относительно других членов Британской королевской семьи: Elena, принцессы Андреевны вообще хохотушки, неудивительно, а вот Карла Филипыча, да и Вильгельма Карлыча разобрало не на шутку [Там же]. Интересным представляются варианты имен Вильгельм, Карл- 
традиционных для передачи англоязычных антропонимов William, Charles в русской лингвокультуре. Использование фамильярно-разговорных вариантов отчеств на -ич / blч показывает ироничное отношение комментирующих к происходящему событию и людям, участвующим в нем. В приведенном примере пользователи описывают реакцию принцесс Беатрисы и Евгении Йоркских, дочерей принца Эндрю, Чарльза, принца Уэльского и Уильяма, герцога Кэмбриджского, на выступление епископа Майла Карри на свадьбе принца Гарри и Меган Маркл.

Отметим еще один вариант модифицированного антропонима в комментарии в адрес принца Луи, сына герцогов Кэмбридских. Оним создан по той же схеме, но с использованием матронима: Какой славный “Луишка Катеринович”, так на Кейт похож, а об иных фото и сказать нечего ... [Там же]. Используя матроним, образованный от имени матери Луи - Кэтрин, русскоязычный пользователь подчеркивает свое восприятие герцогини Кембриждской как значительной фигуры. Кроме того, стоит отметить и необычную, деминутивную форму имени Луи, образованную суффиксальным способом.

Следующим способом модификации иностранных имен являются антропонимы, образованные по схеме «термин кровного родства + личное имя», например, бабуика Лиза, баба Лиза, бабушка Лизавета, деда Чарльз, дедуля Фил: Дедуля Фил сидит с таким видом, что ему не хватает слухового рожка, а Зара и не стремится скрыть, что наблюдает нечто постыдное ...; Баба Лиза тоже крепкий орешек; Доведут бабуику Лизу до инфаркта [Там же].

Другой интересный креативный антропоним для именования Елизаветы II — мадам Лилибет - представляет собой комбинацию британского уменьшительно-ласкательного варианта имени королевы, которым ее называли в детстве - Лилибет, и официального, уважительного обращения к женщине мадам, которое в современном русском языке часто используется в ироничном и негативном смыслах [Зуга, 2018]. Отмечается, что данная лексема имеет ироничный и негативный оттенки значения, когда используется в функции обращения, однако в нашем примере она употреблена как уважительное наименование правящего монарха, обладающего властью: Устоит ли монархия Англии после этой расистской бомбы, брошенной Мегги в Королеву? Да конечно устоит. И не такое бывало. Меган хоть и думает, что собаку съела на интригах, но она и представления не имеет о силе и возможностях Королевы. Мадам Лилибет сожрет ее с потрохами и не подавится [АА].

Одним из редких способов модификации иностранных антропонимов является создание двухкомпонентной окказиональной антропоними- 
ческой конструкции, имитирующей схему «личное имя + фамилия»: $H y$, судя по всему, Гарику Марклу остаётся только заявить, что на самом деле он стариий брат, но БКС запретила ему рождаться первым [Там же]. В данном примере пользователи добавили принцу Гарри фамилию его жены, хотя русская традиция предполагает противоположный процесс: после замужества жена берет фамилию мужа. Таким образом, данным окказиональным антропонимом подчеркивается пренебрежительное отношение аудитории к именуемому лицу как к мужчине, который находится в полном подчинении у жены (подкаблучнику).

Другим примером модифицированной номинации можно назвать использование только фамилии без личного имени, что в русской лингвокультуре может свидетельствовать о фамильярном, чаще пренебрежительном отношении к именуемому лицу. В русскоязычных комментариях такая антропонимическая особенность отмечается в наименовании Меган Маркл, а также супругов Сассекских, при этом англоязычные антропонимы склоняются по правилам русского языка, к примеру: Маркла утверждает, что в свидетельстве о браке, который висит у них в Монтесито на стене в золотой рамочке, стоит дата именно заднего двора без свидетелей; перспектива у марклы / эйча даже ближее чем думают - лишение всех титулов ...; Natalia, Да черт с ним с Байденом. Народ все равно обвинит Марклов [Там же].

Кроме того, нами выявлена окказиональная замена исходного антропонима русским именем: в комментариях русскоязычных пользователей отмечены подобные замены с русскими именами Игорь и Гаврила / Гавриил и их уменьшительными вариантами: мелкая месть Кетрин за теплую сестринскую дружбу с Гаврилой, папе Чарльзу плевок за ущземление денежек; А вот Гавря, тот подленько со своей семьёй обошёлся; Гаврюша старье донашивает ... иоб жене на новые платья хватило; А вот наша Херцогиня в это время в актрису играет - одна рука на пузе, другая в Гавриилову руку вцепилась - это чтобы с диванчика не упасть от жутких воспоминаний и переживаний; А с чего вы взяли что Игорек чем то опечален? [Там же]. Окказиональные имена принца в приведенных примерах имеют, скорее, шутливый характер. Имя Гавриил устаревшее и сегодня не пользуется популярностью в России, в данном случае Гавриил, Гаврюша - это скорее аллюзия, намек на персонажа из советского мультфильма «Каникулы в Простоквашино» бычка Гаврюшу, который известен своим добрым и покладистым характером, а апеллятив антропонимического происхождения гавря / гаврик в некоторых русских говорах используется в значениях 'простак, простофиля, глупец', 'неавторитетный, неуважаемый человек’ [Родионова, 2005, с. 162-189]. 
Подобная тенденция наблюдается и при именовании герцогинь Сассекской и Кембриджской. К примеру, для наименования Меган Маркл пользователи сети выбирают простонародное русское имя Марфа и его уменьшительную форму Марфуша, а также уничижительную форму имени Манька: Блин, эта Марфа, если присмотреться, такая стремная; такими темпами Гарик с Манькой занервируют старых и расчистят досрочно брату путь к трону, а тот и не при делах! [AА]. Для наименования Кэтрин Миддлтон используется имя Катерина и его варианты Катя, Катюха, Катюша: Как же мне нравится Катерина!; Хочется, чтобы королевой Великобритании стала Катюша!; Есть Виля с Катюхой и тремя отпрысками. Что надо от Гарика? [Там же]. Королеву Елизавету русскоязычные пользователи именовали Лизой и Лизаветой: Кого безумно жалко - так это Лизавету [Там же].

Следует отметить, что некоторые из приведенных выше аллюзивных антропонимов (Гаврюша, Марфуша, Манька) содержат культурно-исторический компонент, присущий русской лингвокультуре, а именно «“аккумулируют" коннотации, отражающие позитивное или негативное общественное отношение к ним» [Сысоева, 2019, с. 215].

Учитывая экспрессивную внешнюю форму подобных номинативных единиц, которые употреблены не в полной исходной форме, мы можем утверждать, что выбор этих экспрессивно-оценочных антропонимов обусловлен намерением выразить личное отношение русскоязычных пользователей к обсуждаемым личностям. При этом некоторые варианты упомянутых номинативных единиц обладают негативной коннотацией в русских говорах [Родионова, 2005], что подтверждает факт актуализации социокультурной коннотации окказиональных антропонимов.

Онимизация имен нарицательных («переход имени нарицательного в имя собственное и его дальнейшее становление и развитие в любом разряде онимов» [Милль, 2011, с. 95]) является одним из способов модификации антропонимов в различных языках. К примеру, в русскоязычных комментариях нами были отмечены адаптированные заимствования таких английских окказиональных антропонимов, как аппелятивы-акронимы Хаз (слоговое сокращение от англ. Husband - pус. муж) и Эйч (от англ. $H$ - Harry) для именования принца Гарри; Монтеситские - оттопонимный окказиональный антропоним, образованный от названия города Монтесито, штат Калифорния, США, где проживает чета герцогов Сассекских. Отказ от использования имени в пользу подобных апеллятивов также свидетельствует об ироничном, пренебрежительном отношении аудитории к называемому лицу: А маркла потом будет трещать, дескать, “Уильям не был в военной форме, потому что всегда завидовал Хазу и старался 
походить на младмего брата"; Она его Эйч назвала, но не Хаз; Может Монтеситские стесняются лица своего ребенка? [АА].

Одним из популярных способов модификации антропонимических единиц в интернет-сфере является аббревиация. Полученный антропоним, по мнению лингвистов, выполняет не только компрессивную, но и экспрессивную и стилистическую функции [Антонов, 2013]. В комментариях русскоязычных пользователей Интернета можно встретить следующие русские и заимствованные английские аббревиатурные антропонимы: $E I I$, $E 2$ (королева Елизавета II), $M$ (Меган), $M$. $M$. и $M M$ (Меган Маркл), $\Gamma$ и $M$ (Гарри и Меган), МГ (Меган и Гарри), $Г$ (Гарри), $M \& H$ (Меган и Гарри), $H \& M$ (Гарри и Меган), например: Но М\& Н не успокоились, в интервью погрозили королеве и заявили, что борьба ещё впереди, и они ещуё вернутся; Наверное больше $\boldsymbol{\Gamma}$ и М будет не о чем рассказывать до тех пор пока не родится след. Ребёнок ...; $\mathbf{E 2}$ очень умная Королева.. думаю, она все-таки найдет способ [Там же].

Интересными представляются также и созданные путем контаминации акронимы-сокращения от первых слогов имен Меган Маркл и принца Гарри, к примеру: У Елизаветы есть мошуный тыл - ее семья. А что есть у Мегариков?; Удивительное дело: почему практически на всех фото МеХарики так нелепьл?!; Старая гвардия может и будет держать дистанцию, а вот молодые леди и виконты встанут на защиту БКС, смогут так учтиво по щуам надавать, что МаГлам мало не покажется! [Там же]. Следует отметить, что в отношении других членов Британской королевской семьи подобный способ модификации антропонимов в русскоязычной интернет-сфере не отмечается.

Используются интернет-коммуникантами и возможности ономастической игры, в частности приемы графического словообразования. Ономастическая игра, по мнению лингвистов, «активно эксплуатирует именно социокультурный шлейф, который составляет коннотат соответствующего онима» [Гридина, 2011, с. 219]. Большинство подобных окказионализмов на основе фонематической субституции созданы для наименования Меган Маркл, герцогов Сассекских, их сына Арчи Сассекского, к примеру: МегаМаркла, Марк Клуша, Мракла / Мракльл, Мыркла, Муркл, Марклака, Шмаркля, Херцогиня, Сусики, Суслики, Харчонок (И теперь она всему миру покажет КТО такая МегаМаркла, да так, что королева на коленях будет умолять её вернуться!; Опять святая Мракла в цчентре. А эти, двое, так, фон; Хохотала долго! Бедная Мыркла; Не надо было с биглем рядом МаркКлуие интервью давать; Едет один, без Марклаки; По поводу фото, на первом она явно видела фотографа и ульбается в камеру, непонятно за что засудили издание, ради того чтобы бабла срубить и 
самый справедливый суд на свете (суд США), пародоксальнылм образом встал на сторону Сусликов ...; Как удобен накладной живот! Посадила на него своего Харчонка - и таскай [AА]. Ономастическая игра в данных примерах несет ярко выраженную экспрессивную функцию. Использованный для создания указанных антропонимов прием какэмфатона, то есть «случайного, а иногда и нарочитого стечения звуков / или слогов, омофонически напоминающих совсем другие слова, с совершенного иным значением, обычно сниженным, смешным или грубым по сравнению со значением исходного слова» [СЛТ, 2005, с. 187-188], указывает на ироническую / сатирическую коннотацию употребленных лексических единиц. Функционирование подобных окказиональных антропонимов отражает личностное отношение аудитории к именуемому лицу и его субъективную оценку, в исследуемых случаях чаще - негативную. Лингвисты отмечают, что «наличие словообразовательного элемента с негативной коннотацией относит подобные окказионализмы к инвективной и обсценной лексике» [Бонджолова, 2020, с. 360].

Уменьшительно-ласкательные суффиксы русского языка, которые, по мнению лингвистов, можно отнести к словообразовательным средствам экспрессивного характера [Карпенко 1980; Крылова, 2016, Медведева, 2013], чаще всего использовались в русскоязычных комментариях для наименования многих известных королевских персон. Например, антропонимы-дериваты для наименования королевы Елизаветы, принца Чальза, принца Гарри и Меган Маркл были образованы при помощи суффисков -к-, -ешк, -ушк, -ха, -ша, -уся, которые характеризуются эмоционально-оценочной семантикой. Форма имени Лизка выражает фамильярную субъективную оценку говорящим объекта номинации (выражение пренебрежения), которая репрезентируется посредством эмоционально-экспрессивного суффикса -ка: Лизка рядом с ним везде цветет, а он сдержан [AА]. Такую же стилистическую окраску можно отметить и в случае создания окказиональных антропонимов от имени принца Чарльза: Да пусть они там все перегрызут друг друга - мне то что? Вам реально жаль Чарлика?!; А так то значит не “тянет” Чарльзушка на Короля ... [Там же].

Подобный способ окказионального словообразования использовался для модификации имени принца Уильяма, к примеру: ну у катьки с вилькой ульбки то тоже отрепетированные) ну да ладно, это их работа ... [Там же]. Данный антропоним представляет собой усечение от имени Уильям (в русской традиции встречается также написание Вильям) с русским суффиксом -ка.

В комментариях пользователей можно встретить несколько вариантов окказиональных антропонимов для называния Меган Маркл с помощью 
уменьшительных суффиксов снисходительно-грубой, пренебрежительной семантики:

- образованные от личного имени Меган - Меганка (почему вам Меганка не нравится?), Мегашечка (И жо же то делается то???!!! Гарюсик с мегашечкой два часа страдали давали интервью, а тугая бкс все не бежит к ним извиняться), Мегушка (Разговорь, обвинения, обиды ... Я жду другого. Когда БКС обвинит Мегуику в воровстве драгоченностей), Мегаха (Да не было у них траура! А про сайт забыли просто, ну не успевает Мегаха!), Мегуся (А Мегуся вся такая внезапная и противоречивая) [Там же]. Интересным представляется окказиональный антропоним Меганша, отмеченный нами в одном из комментариев, поскольку в русском языке суффикс-ша присоединяется обычно к первому слогу имени, оканчивающемуся на гласный (Гриша, Алеша, Глаша), и почти никогда не употребляется в именах, имеющих после начального слога $-н$ (редкое исключение составляет разве что окказиональное словообразование: Ниниа): Надо убрать этих лишних из семьи, а сделать это надо по умному, Англия правит миром, что они с Меганшей не справяться, мне даже кажется, что это и есть главное подставное лицо», «Не понимаю возмущения кого бы то ни было (общественности, королевы и прочая и прочая) по поводу “убытия” Гарика с Меганшей [Там же].

- образованные от аббревиатуры $M M$ - Мемка, Мэмэшка, Ммешка (То есть, англичане, особливо члень БКС, настолько глупь, что озаботились изветом кожи дитя только тогда, когда Мемка забеременела?; У ммешки на ногах опять цишки выросли, операцию ж делала; Как уже надоела эта Мэмэика. Я не могу представить, что у нее ещуе есть фанаmbl) [Там же].

Окказиональные деривативы с уменьшительным суффиксом - $к-$ употребляются и в отношении принца Гарри: Гарик / Гаррик, Гарька, Гарюсик (Гарик просто попался под руку, видимо был какой-то косяк, за который ухватились, чтобы начать прочесс развала монархии; Не-не, Марклуша про БКС и Гарьку ни разу не сльшиала-ни фото не видела; И жо же то делается то???!!! Гарюсик с мегашечкой два часа страдали давали интервью, а тугая бкс все не бежит к ним извиняться [Там же]. Использование уменьшительных имен характерно для личного общения с близкими людьми. При помощи подобных окказиональных антропонимов русскоязычные пользователи сети старались выразить фамильярное отношение и иронию по отношению к соответствующим лицам. Кроме того, по мнению лингвистов, «в литературной норме закреплена негативная окраска именных форм с суффиксом -к-» [Рут, 2001, с. 64].

Суффикс -онок использовался русскоязычными пользователями для создания окказионального антропонима Арчонок - от имени сына четы 
Сассекских Арчи: И из-за Филиппа героев фотки, даже, Арчонка, никто не обсуждает [AА]. Следует отметить, что данный суффикс в русском языке не используется для создания деминутивных антропонимов, а служит для наименования детей, представителей социальной прослойки, профессии, национальности, кроме того, детёнышей животных, имен существительных мужского рода с уменьшительно-ласкательным или только с ласкательным значением [СТСРЯ].

Анализ семантики суффиксов, использованных русскоязычными пользователями для создания модифицированных антропонимов членов Британской королевской семьи, показал, что данные словообразовательные элементы не только выполняют эмоционально-экспрессивную функцию, но и позволяют говорящему «ярче выразить нужный эмоциональный нюанс» [Карпенко, 1980, с. 100].

Одним из самых редких способов создания окказиональных антропонимов членов Британской королевской семьи можно назвать усечение. Данный способ отмечен нами всего в двух случаях: он использован для модификации имени принца Уильяма при помощи сочетания усечения и суффиксации (см. пример выше) и для наименования четы Уильяма и Кейт (У Кембри всегда пластмассовые ульбки). В данном примере Кембри представляет собой усечение от титула пары — герцоги Кембриджские.

\section{4. Заключение}

Интернет, являясь на сегодняшний день одной из самых популярных площадок общения, дает пользователям широкие возможности для творчества и для того, чтобы выразить свое отношение к событиям в мире, в том числе и посредством модифицикации иностранных антропонимов.

В результате изучения антропонимов, называющих членов Британской королевской семьи, мы получили следующие статистические результаты. Анализ словообразовательных моделей изученных лексических единиц показал, что самым продуктивным способом является суффиксация: данный способ использовался в 26 \% случаев. Способом сокращения было образовано 22 \% антропонимов. Ономастическая игра и окказиональная замена использовались примерно в равном количестве случаев - 16 \% и 15 \% антропонимических единиц. Другие способы использовались реже: схема «личное имя + патроним / матроним» отмечена в 8 \% случаев, схема «термин кровного родства + личное имя» - в $6 \%$, апеллятивы - в $3 \%$, усечение - $2 \%$, схема «личное имя + фамилия» - $1 \%$, схема «обращение + уменьшительно-ласкательная форма личного имени» - 1 \%, замещение личного имени фамилией - 1 \%. Во всех случаях модифицированные окказиональные антропонимы имеют оценочную семантику. 


\section{ИСТОЧНИКИ И ПРИНЯТЫЕ СОКРАЩЕНИЯ}

1. АА - Архив авторов, собранный на интернет-платформе «Яндекс.Дзен». - Режим доступа : https://zen.yandex.ru/ (дата обращения 23.06.2021).

2. СЛТ, 2005 - Ахманова О. С. Словарь лингвистических терминов / О. С. Ахманова. - Изд. 3-е. - Москва : КомКнига, 2005. - 576 с. - ISBN 5-354-00600-7.

3. СТСРЯ - Современный толковый словарь русского языка Ефремовой [Электронный ресурс]. - Режим доступа : https://dic.academic.ru/contents.nsf/efremova/ (дата обращения 03.05.2021).

\section{ЛитеРАТУРА}

1. Антонов В. П. Лингвопрагматический потенциал аббревиатурных антропонимов современной эпохи / В. П. Антонов // Вестник Красноярского государственного педагогического университета имени В. П. Астафьева. — 2013. — № 4 (26). - С. 189-194.

2. Бонджолова В. Ц. Окказиональные трансформации антропонимов как инвективная лексика / В. Ц. Бонджолова // Медиалингвистика. — 2020. — № 7 (3). — С. $357-$ 367. — DOI: 10.21638/spbu22.2020.307.

3. Гридина T. А. Этносоциокультурный контекст ономастической игры / Т. А. Гридина // Политическая лингвистика. - 2011. — № 1 (35). - С. 219-223.

4. Гудым Г. В. Антропонимика интернет / Г. В. Гудым // Культура. Наука. Интеграция. - 2014. - № 1 (25). - С. 73-76.

5. Дьяченко В. В. Основные способы образования субстандартных антропонимов в английском и русском языках / В. В. Дьяченко // Вестник Ставропольского государственного университета. - 2007. — № 48. - С. 58-65.

6. Замальдинов B. E. Антропонимы как источник новообразований в языке СМИ и интернет-коммуникации / В. Е. Замальдинов // Вестник Удмуртского университета. Серия История и филология. - 2019. - Т. 29. - № 3. - C. 435-441. - DOI: 10.35634/2412-9534-2019-29-3-435-441.

7. Зимина И. И. К вопросу об особенностях виртуальных антропонимов в интернет-коммуникации / И. И. Зимина, Н. В. Саварцева // Диалог культур - диалог о мире и во имя мира. - 2014. - № 2. - С. $67-72$.

8. Зуга О. В. “Мадам!” оскорбление или вежливое обращение? / О. В. Зуга // Вестник Удмуртского университета. Серия История и филология. - 2018. - Т. 28. № 2. - С. $248-253$.

9. Карпенко А. Ю. Деминутивное антропонимическое словообразование (на материале русских говоров юга Украины) / А. Ю. Карпенко // Вопросы ономастики. Свердловск : Издательство Уральского университета, 1980. - С. 99-110.

10. Крылова А. Г. Словообразовательные средства экспрессивности в системе антропонимов (на примере произведений Ю. В. Буйды) / А. Г. Крылова // Вестник Московского государственного областного университета. Серия : Русская филология. 2016. — № 3. - C. 36 - 43. — DOI: 10.18384/2310-7278-2016-3-36-43

11. Медведева К. М. Семантика эмоционально-экспрессивных суффиксов квалитативных форм русских антропонимов / К. М. Медведева // Молодой ученый. — 2013. № 7 (54). - C. $487-490$.

12. Милль Дж. Сm. Система логики силлогистической и индуктивной / Дж. Ст. Милль. - Москва : Ленанд, 2011. — 832 с. — ISBN 978-5-9710-0181-2. 
13. Родионова И. В. Характерологические номинации антропонимического происхождения в русских народных говорах / И. В. Родионова // Русский язык в научном освещении. - 2005. — № 2 (10). - С. 159-189.

14. Рут M. Э. Антропонимы : размышления о семантике / М. Э. Рут // Известия Уральского государственного университетата. — 2001. - № 20. - С. 59-64.

15. Сысоева E. C. Аллюзия в семантике английских оценочных антропонимов / Е. С. Сысоева // Мир. Человек. Язык : сборник научных трудов. - Владимир : Владимирский государственный университет имени Александра Григорьевича и Николая Григорьевича Столетовых, 2019. - С. 211-216.

\section{MATERIAL Resources}

AA - An archive of authors collected on the Yandex. Zen Internet platform. Available at: https://zen.yandex.ru/ (accessed 23.06.2021).

SLT - Akhmanova, O. S. (2005). Dictionary of linguistic terms. Moscow: KomKniga. 576 p. ISBN 5-354-00600-7. (In Russ).

STSRYA - Modern explanatory dictionary of the Russian language by Efremova. Available at: https://dic.academic.ru/contents.nsf/efremova/ (accessed 03.05.2021). (In Russ).

\section{REFERENCES}

Antonov, V. P. (2013). Linguopragmatic potential of abbreviated anthroponyms of the modern era. Bulletin of the Krasnoyarsk State Pedagogical University named after V. P. Astafyev, 4 (26): 189-194. (In Russ).

Bondzholova, V. Ts. (2020). Occasional transformations of anthroponyms as an invective vocabulary. Media linguistics, 7 (3): 357-367. DOI: 10.21638 / spbu22. 2020. 307. (In Russ).

Dyachenko, V. V. (2007). The main ways of forming sub-standard anthroponyms in English and Russian. Bulletin of the Stavropol State University, 48: 58-65. (In Russ).

Gridina, T. A. (2011). Ethnosociocultural context of the onomastic game. Political Linguistics, 1 (35): 219 -223. (In Russ).

Gudym, G. V. (2014). Anthroponymy of the Internet. Culture. The science. Integration, 1 (25): 73-76. (In Russ).

Karpenko, A. Yu. (1980). Deminutive anthroponymic word formation (based on the material of Russian dialects of the south of Ukraine). In: Questions of onomastics. Sverdlovsk: Ural University Press. 99-110. (In Russ).

Krylova, A. G. (2016). Word-forming means of expressiveness in the system of anthroponyms (on the example of the works of Yu. V. Buida). Bulletin of the Moscow State Regional University. Series: Russian Philology, 3: 36 - 43. DOI: 10.18384/23107278-2016-3-36-43. (In Russ).

Medvedeva, K. M. (2013). Semantics of emotionally expressive suffixes of qualitative forms of Russian anthroponyms. Young Scientist, 7 (54): 487-490. (In Russ).

Mill, J. St. (2011). System of syllogistic and inductive logic. Moscow: Lenand. 832 p. ISBN 978-5-9710-0181-2. (In Russ).

Rodionova, I. V. (2005). Characterological nominations of anthroponymic origin in Russian folk dialects. Russian language in scientific coverage, 2 (10): 159-189. (In Russ). 
Ruth, M. E. (2001). Anthroponyms: reflections on semantics. Bulletin of the Ural State University, 20: 59-64. (In Russ).

Sysoeva, E. S. (2019). Allusion in the semantics of English evaluative anthroponyms. In: Mir. Person. Language: a collection of scientific papers. Vladimir: Vladimir State University named after Alexander Grigoryevich and Nikolai Grigoryevich Stoletov. $211-216$. (In Russ).

Zamaldinov, V. E. (2019). Anthroponyms as a source of neoplasms in the language of mass media and Internet communication. Bulletin of the Udmurt University. History and Philology series, 29 (3): 435-441. DOI: 10.35634/2412-9534-2019-29-3435-441. (In Russ).

Zimina, I. I., Savartseva, N. V. (2014). On the question of the features of virtual anthroponyms in Internet communication. The dialogue of Cultures is a dialogue about peace and for the sake of peace, 2: 67-72. (In Russ).

Zuga, O. V. (2018). "Madame!" insult or polite treatment? Bulletin of the Udmurt University. History and Philology series, 28 (2): 248-253. (In Russ). 